\title{
Erratum to: Evidence for recombination between vaccine and wild-type mumps virus strains
}

\author{
Wen Zhang • Wei Liu
}

Published online: 26 March 2011

(C) Springer-Verlag 2011

Erratum to: Arch Virol (2010) 155:1493-1496
DOI 10.1007/s00705-010-0733-x

In a paper published last year in Archives of Virology recombination occurring in mumps virus has been reported (Zhang et al., Arch Virol. 2010 Sep;155(9):1493-1496. Epub 2010 Jun 25.). This conclusion was based on the complete genome sequence of mumps virus strain 9218/Zg98 deposited in GenBank in January 2008 by Dubravko Forcic, Zagreb, Croatia (dforcic@imz.hr). Since this sequence proved to be erroneous, the paper has been retracted.

The online version of the original article can be found under doi:10.1007/s00705-010-0733-x.

W. Zhang $(\bowtie)$

School of Medical Science and Laboratory Medicine,

Jiangsu University, 301 Xuefu Road, 212013 Zhenjiang,

Jiangsu, People's Republic of China

e-mail: z0216wen@yahoo.com

W. Liu

Key Laboratory of Medical Molecular Virology,

Institute of Medical Microbiology, Shanghai Medical College,

Fudan University, 200032 Shanghai, China

W. Liu

Institutes of Biomedical Sciences, Fudan University,

200032 Shanghai, China 